\title{
Comparason of extraction methods for PCR detection of Burkholderia cepacia complex (BCC) from cystic fibrosis patients
}

Research Article

\author{
Koray Ergunay ${ }^{1 *}$, Pinar Yurdakul', Burcin Sener ${ }^{1}$, Ugur Ozcelik², \\ Erdem Karabulut ${ }^{3}$, Nural Kiper \\ ${ }^{1}$ Hacettepe University Faculty of Medicine, \\ Department of Microbiology and Clinical Microbiology, \\ Morphology Building 3rd floor, Sihhiye, Ankara, 06100, Turkey \\ ${ }^{2}$ Hacettepe University Faculty of Medicine, Department of Pediatrics, \\ Division of Chest Diseases; Ihsan Dogramaci Childrens' Hospital, \\ Sihhiye, Ankara, 06100, Turkey \\ ${ }^{3}$ Hacettepe University Faculty of Medicine, Department of Biostatistics, \\ Sihhiye, Ankara, 06100, Turkey
}

Received 3 October 2007; Accepted 18 November 2007

\begin{abstract}
Direct detection of Burkholderia cepacia complex (BCC) and its genomovars from sputum by molecular tests emerges as a method for rapid identification. In this study, four DNA extraction methods were evaluated for the identification for BCC from sputum of CF patients. Sputa from 28 CF patients were aliquoted and spiked with BCC reference strain. Boiling, phenol-chloroform, CTAB methods and a commercial spin column kit was used for DNA extraction. Total DNA yields were determined by spectrophotometry and single-round recA PCR was used for detection of BCC. No significant difference was observed in DNA yields from different extraction methods. Lower limit of detection for recA PCR was determined as $10^{6} \mathrm{cfu} / \mathrm{ml}$. Amplification was observed in $7 / 16(43.7 \%)$ of sputa for boiling, $8 / 16(50 \%)$ of sputa for CTAB and 13/16 (81.2\%) of sputa for phenol-chloroform method and spin column kit in the assay sensitivity range determined in the study. Phenol-chloroform and commercial spin column kit were found to be better suited for DNA purification from sputum of CF patients for BCC identification. Diagnostic impact of single-round recA PCR directly from sputum was limited to chronically-infected patients.
\end{abstract}

Keywords: DNA extraction • PCR • Burkholderia • Burkholderia cepacia complex • Cystic fibrosis

(c) Versita Warsaw and Springer-Verlag Berlin Heidelberg.

\section{Introduction}

Burkholderia cepacia complex (BCC) is a group of closely related gram-negative bacteria that consists of at least nine genetically distinct members referred collectively as genomovars [1]. Originally identified as plant pathogens, species belonging to BCC have been recognised as important opportunistic bacterial agents not only in persons with cystic fibrosis (CF) but also for immunosuppressed patients. BCC infection has been shown to be an important threat for CF patients, owing to dramatical increase in symptoms and decline in pulmonary functions; besides causing a potentially fatal necrotizing pnemonitis with bacteremia, called as Cepacia Syndrome in $20 \%$ of infected persons. Patient to patient transmission (and potential for nosocomial spread) and multi-drug resistance are other possible consequences of BCC infection that contributes to increased morbidity and mortality in CF. Thus, reliable detection of organisms belonging to $\mathrm{BCC}$ is crucial for the optimal clinical management of $\mathrm{CF}$ patients, as well as for infection control purposes [1,2].

Closely related species like BCC are generally difficult to identify by conventional phenotypic and

*E-mail: ekoray@hacettepe.edu.tr 
biochemical tests. It is reported that commercial systems lack sufficient sensitivity and specificity for accurate identification of bacteria belonging to BCC group [3,4]. Recently, PCR-based methods are emerging as useful diagnostic tools for rapid identification and typing of BCC, also enabling direct detection of bacterial DNA from patient's sputum $[2,5,6]$. The ability of these assays to detect BCC in sputum is dependent on both selected target sequence and efficiency of DNA extraction procedure. Sputum has previously shown to contain several PCR inhibitors and failure to remove these enzymatic inhibitors and adequately extract DNA could result in false-negative results $[5,7]$. In this study, we compare the efficiency of three commonly used standard DNA extraction procedures: boiling, phenol-chloroform and cetyltrimethylammonium bromide (CTAB) methods, and a commercial spin-column kit for the extraction for Burkholderia cepacia complex DNA for PCR from sputum of CF patients. Sensitivity and diagnostic impact of recA PCR directly performed on sputum samples is also evaluated.

\section{Material and Methods}

\subsection{Bacterial Strains}

B.cepacia complex (KK 7394 Neqas, United Kingdom) was used as the reference strain for the study. Prior to spiking and analysis, B.cepacia complex reference strain was grown on $5 \%$ sheep blood agar and then further tested for growth on selective OFPBL agar (Oxidative, Fermentative, Polymyxin B, Bacitracin, Lactose) at $37^{\circ} \mathrm{C}$. Fresh bacterial suspensions from overnight cultures were prepared in sterile saline and used to spike sputum specimens. DNA extracted from bacterial cultures by High Pure PCR Template Kit ${ }^{\mathrm{TM}}$ (Roche Diagnostics, Germany) was used as a positive control for recA PCR.

Astrain of Pseudomonas putida, identified previously from a clinical sample by PHOENIX ${ }^{\mathrm{TM}}$ (Becton-Dickinson, United Kingdom) automated identification system was used as negative control in the study. The strain was cultivated on sheep blood agar plates and bacterial DNA was extracted by High Pure PCR Template Kit ${ }^{T M}$ (Roche Diagnostics, Germany). Purified DNAs were used as negative controls.

\subsection{Study Population}

Sputum samples of 28 cystic fibrosis patients that had attended to Hacettepe University Department of Pediatrics Chest Diseases Clinic were included in the study after informed consent and Hacettepe University
Ethics Committee's approval. Sputum samples were collected in sterile screw-capped dishes and immediately transferred to the laboratory. Sputa were then randomly assigned to one of seven study groups for spiking with various amounts of bacteria.

\subsection{Sample Processing}

Sputum samples from each CF patient were homogenized by vigorous vortexing and separated into four 200 - $500 \mu$ l aliquots and the remaining amount were stored for bacteriological analysis. All four aliquots from each patient were spiked with BCC reference strain with approximate final concentrations of $10^{9}$ to $10^{3} \mathrm{cfu} / \mathrm{ml}$ according to study groups. A total of seven study groups containing $10^{9}, 10^{8}, 10^{7}, 10^{6}, 10^{5}, 10^{4}$ and $10^{3} \mathrm{cfu} / \mathrm{ml}$ of BCC, each composed of sputa from four CF patients were prepared. All samples were then thoroughly mixed and an equal amount of freshly prepared Sputolysin (Sigma, United Kingdom) was added to each sample. The samples were then incubated at $37^{\circ} \mathrm{C}$ for 30 minutes as described previously [2,8].

\subsection{DNA extraction methods}

\subsubsection{Boiling}

Processed sputum samples were centrifuged at 10.000 $\mathrm{g}$ for 10 minutes. The supernatant was discarded and the pellet was resuspended in $200 \mu \mathrm{ITE}(10 \mathrm{mM}$ TRIS-HCL [pH:8.0], 1mM EDTA) and briefly mixed by vortexing. Samples were then kept at $100^{\circ} \mathrm{C}$ in a heat block for 10 minutes. After an incubation at $37^{\circ} \mathrm{C}$ for 1 hour with addition of $150 \mu \mathrm{g}$ lysozyme (Sigma, United Kingdom) to each sample for achieving complete bacterial lysis, samples were centrifuged at $12.000 \mathrm{~g}$ for 5 minutes and the supernatant was used for PCR.

\subsubsection{Phenol-chloroform and CTAB extraction}

Following incubation at $55^{\circ} \mathrm{C}$ overnight in $500 \mu \mathrm{l}$ digestion buffer (10 mM Tris-HCL, $\mathrm{pH}: 8.0,150 \mathrm{mM} \mathrm{NaCl}$, $25 \mathrm{mM}$ EDTA, 0.5\% SDS [v/v], $20 \mathrm{mg} / \mathrm{ml}$ Proteinase $\mathrm{K}$ ), standart phenol-chloroform method was employed as previously described [9].

For CTAB extraction method, $30 \mu \mathrm{l}$ of $10 \%$ SDS and $3 \mu$ of proteinase $\mathrm{K}(20 \mathrm{mg} / \mathrm{ml})$ (Sigma, United Kingdom) was added to $500 \mu \mathrm{l}$ sample, mixed thoroughly and incubated at $37^{\circ} \mathrm{C}$ overnight. Then, standard procedure was performed as described before [10].

\subsubsection{Commercial spin column kit}

High Pure PCR Template Kit ${ }^{\mathrm{TM}}$ (Roche Diagnostics, Germany) was used according to the manufacturers' instructions. 


\subsubsection{Isolation and Identification of B.cepacia complex} Ten $\mu \mathrm{l}$ of remaining sputa from each patient were processed with Sputolysin as described above and inoculated simultaneously onto OFPBL agar (Oxidative fermentative, polymyxin B, bacitracin, lactose) and blood agar plates supplemented with $5 \%$ sheep blood and incubated at $37^{\circ} \mathrm{C}$ for $48-72$ hours for the isolation of inherent BCC before spiking with bacteria. Colonies observed on OFPBL agar were tested for oxidase activity and identified using commercially available identification systems if required.

\subsubsection{PCR Detection of B.cepacia complex}

B.cepacia complex recA gene was amplified using BCR-1 and BCR-2 primers, specific for BCC $[2,8]$. For the PCR, $5 \mu \mathrm{l}$ of extracted DNA from each procedure were added to a master mix of $50 \mu \mathrm{l}$ containing $750 \mathrm{mM}$

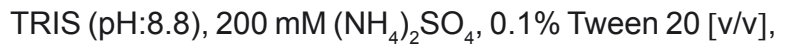
$1.5 \mathrm{mM} \mathrm{MgCl}_{2}, 200 \mu \mathrm{M}$ of each deoxyribonucleotides, 25 pmol of primers, 0.7 units of Taq DNA Polymerase. The thermocycling program consisted of an initial denaturation at $96^{\circ} \mathrm{C}$ for 7 minutes followed by denaturation at $96^{\circ} \mathrm{C}$ for 60 seconds, annealing at $56^{\circ} \mathrm{C}$ for 60 seconds and extention at $72^{\circ} \mathrm{C}$ for 90 seconds for 35 cycles. An extention of 10 minutes at $72^{\circ} \mathrm{C}$ were also performed after amplification. Thermocycling were performed in a PTC-200 Thermocycler (MJ Research, USA). Amplicons of $1040 \mathrm{bp}$ were separated by electrophoresis in $1.5 \%$ agarose gel and visualised under ultraviolet light after staining with ethidium bromide. DNA extraction, PCR and electrophoresis were performed in separate laboratories in order to avoid contamination. All PCR amplifications were done in duplicate.

\subsubsection{Spectroscopic determination of DNA amount} Absorbance values at $260 \mathrm{~nm}\left(\mathrm{OD}{ }_{260}\right)$ were used for calculating the amount of total nucleic acid yields from each extraction method for all samples.

\subsubsection{Statistical Analysis}

Mann-Whitney, Kruskal-Wallis and ANOVA tests were applied where appropriate. $P$ values $<0.05$ were assumed as statistically significant. Data analyses were performed by SPSS ${ }^{\circledR}$ Version 12.0.

\section{Results}

\subsection{Isolation of B.cepacia complex from sputa}

BCC was not isolated in any of the patients' sputa evaluated prior to spiking in the study population.

\subsection{DNA yields from extraction methods}

Means of total DNA yield was calculated as $111.8 \mu \mathrm{g}$ (median: 34.5, range: 0.00-620.0) for boiling; $44.4 \mu \mathrm{g}$ (median: 23.6, range: 4.50-139.0) for phenol chloroform; $97.3 \mu \mathrm{g}$ (median: 11.7, range:1.25-620.0) for CTAB and $17.8 \mu \mathrm{g}$ (median: 10.5, range: 1.00-79.0) for spin column methods. The differences of purified nucleic acid amounts among extraction methods were not statistically significant ( $p: 0.065)$. For sputa containing $10^{9}-10^{6} \mathrm{cfu} / \mathrm{ml}$ bacteria, differences of total DNA yield were also not statistically significant (p:0.157). Nucleic acid yields and recA PCR detection rates for this group are given in Table 1.

\subsection{B.cepacia complex recA PCR}

BCC DNA was detected in 7 out of $28(25 \%)$ samples by boiling; in 8 out of $28(28.5 \%)$ by CTAB; 13 out of $28(46.4 \%)$ by phenol-chloroform and spin column kit. BCC concentrations lower than $10^{6} \mathrm{cfu} / \mathrm{ml}$ in 12 sputum samples could not be detected by PCR with any of the extraction method employed. When calculated for $10^{9}-10^{6} \mathrm{cfu} / \mathrm{ml}$ concentration range, detection rate was $7 / 16(43.7 \%)$ for boiling, $8 / 16(50 \%)$ for CTAB and $13 / 16(81.2 \%)$ for phenol-chloroform method and spin column kit. Results of BCC recA PCR according to the final concentration of bacteria in sputum and extraction method above $10^{6} \mathrm{cfu} / \mathrm{ml}$ were given in Table 1.

Boiling method could detect BCC nucleic acids in 3 out of 4 samples in $10^{9} \mathrm{cfu} / \mathrm{ml}$ group and 2 out of 4 in $10^{8}$ and $10^{7} \mathrm{cfu} / \mathrm{ml}$ groups, giving negative results for all samples containing $10^{6} \mathrm{cfu} / \mathrm{ml}$ of bacteria. CTAB methods was also unable to identify any samples with $10^{6} \mathrm{cfu} / \mathrm{ml}$ of BCC, but detecting $50 \%$ and $75 \%$ of the samples in $10^{7} \mathrm{cfu} / \mathrm{ml}$ and $10^{8}-10^{9} \mathrm{cfu} / \mathrm{ml}$ groups respectively (Table 1). All PCR positive samples purified by boiling and CTAB methods were also positive by phenol-chloroform method and spin column kit. Phenol-chloroform extraction method identified BCC nucleic acids in 3 out of 4 samples for sample groups with $10^{6}, 10^{7}$ and $10^{8} \mathrm{cfu} / \mathrm{ml}$ of bacteria and detecting all samples with a concentration of $10^{9} \mathrm{cfu} /$ $\mathrm{ml}$ (Table 1). Amplification of two samples having $10^{6}$ $\mathrm{cfu} / \mathrm{ml}$ of BCC was only accomplished by phenolchloroform method. Commercial spin column kit identified target sequences in all samples for sputa with a final bacterial concentration of $10^{9}-10^{7} \mathrm{cfu} / \mathrm{ml}$. For sputa containing $10^{6} \mathrm{cfu} / \mathrm{ml}$ of BCC, amplification was successful in 1 out of 4 samples (Table 1). 
Table 1. Nucleic acid yields and recA PCR detection rates of various nucleic acid extraction methods for sputa containing $\geq 106 \mathrm{cfu} / \mathrm{ml}$ of BCC.

\begin{tabular}{|c|c|c|c|c|c|c|c|c|}
\hline \multirow[t]{2}{*}{ Extraction Method } & \multirow{2}{*}{$\begin{array}{l}\text { Number } \\
\text { of } \\
\text { Samples }\end{array}$} & \multicolumn{4}{|c|}{ Total nucleic acid $(\mu \mathrm{g})$} & \multicolumn{3}{|c|}{ \# of recA PCR positive samples } \\
\hline & & Mean & Median & Range & $10^{9} \mathrm{cfu} / \mathrm{ml}$ & $10^{8} \mathrm{cfu} / \mathrm{ml}$ & $10^{7} \mathrm{cfu} / \mathrm{ml}$ & $10^{6} \mathrm{cfu} / \mathrm{ml}$ \\
\hline Boiling & 16 & 56.20 & 34.50 & $2.00-191.00$ & $3 / 4(75 \%)$ & $2 / 4(50 \%)$ & $2 / 4(50 \%)$ & $0 / 4$ \\
\hline Phenol- chloroform & 16 & 24.80 & 15.25 & $7.25-71.50$ & $4 / 4(100 \%)$ & $3 / 4(75 \%)$ & $3 / 4$ (75\%) & $3 / 4(75 \%)$ \\
\hline CTAB & 16 & 15.20 & 10.63 & $1.75-40.50$ & $3 / 4$ (75\%) & $3 / 4$ (75\%) & $2 / 4$ (50\%) & $0 / 4$ \\
\hline Spin Column Kit & 16 & 12.00 & 8.00 & $1.00-44.00$ & $4 / 4(100 \%)$ & $4 / 4(100 \%)$ & $4 / 4(100 \%)$ & $1 / 4(25 \%)$ \\
\hline
\end{tabular}

\section{Discussion}

Bacteria belonging to $\mathrm{BCC}$, with their considerable impact on morbidity and mortality of CF patients, require special care for accurate isolation and identification. Laboratory identification of BCC up to genomovar level is also crucial since certain genomovars are reported to be highly transmissible between CF patients and stringent infection control policies should be undertaken to prevent transmission to other patients $[1,8,11]$. The discrepancy between results obtained by phenotypic and molecular detection techniques is also of importance for the identification of BCC. It has been reported that certain bacterial strains can be misidentified as members of the BCC by commercial identification systems $[3,4,12]$. It was generally accepted that because of low specificity, differences in methodologies and phenotypic variations that can occur within species, the confirmation of BCC identification by phenotypic tests should be made by a reference laboratory $[13,14]$. Molecular methods are emerging as reliable tools for accurate BCC identification [15]. Previously, we have noted that the identification of BCC isolates via commercial phenotypic systems need to be confirmed by molecular methods due to discrepant results obtained from phenotypic tests [16].

Direct detection of pathogens by molecular methods in clinical specimens offer a useful alternate diagnostic tool in cases where phenotypic methods exhibit reduced sensitivity and / or specificity; such as BCC infections in CF. The main objective of this study was to evaluate the commonly used nucleic acid extraction techniques for PCR detection of BCC in sputum.

Diagnostic sensitivity of PCR from sputum may be influenced by various factors, namely the copy number of target sequence in the sample, size of the target amplicon, quality of the clinical specimen and the presence of PCR inhibitors. It is not clear whether sputa from CF patients have altered characteristics that have to be taken into consideration when performing molecular tests directly from these clinical specimens. In this study, phenol-chloroform and CTAB as standard manual extraction methods, a commercial spin column based extraction kit and boiling method that is very practical and effective in some applications, were evaluated for PCR amplification of BCC directly from experimentallyspiked sputum samples of CF patients.

A well-defined recA based PCR protocol was used for the detection of BCC. B.cepacia complex can be detected and distinguished by sequence variations in $16 S$ rRNA and recA gene; but very high specificity of $r e c A$ gene for pathogens in BCC and possibility of accurate genomovar identification by Restriction Fragment Length Polymorphism (RFLP) or other methods make this locus a good target for diagnostic PCR [2,5].

Although no statistically significant difference in DNA yields obtained from different extraction techniques determined by spectroscopy was observed ; phenolchloroform extraction and spin column kit performed better for recA PCR, identifying 13 of 28 (46.4\%) of the experimentally-spiked samples. This detection rate is a result of presence of $\leq 10^{6} \mathrm{cfu} / \mathrm{ml} \mathrm{BCC}$ in twelve of the samples, which were below the limit of detection for $r e c A$ PCR observed in this study. Boiling and CTAB methods could only detect target sequences in a total of 6 and 8 sputum samples respectively, which also gave positive results via other extraction methods. For sputa spiked for a final concentration of $10^{6} \mathrm{cfu} / \mathrm{ml}$ of $\mathrm{BCC}$, target nucleic acids were detected in $75 \%$ of samples after purification by phenol-chloroform method, from which only one could be amplified after purification by spin column kit. Interestingly, all samples in $10^{7}-10^{9} \mathrm{cfu} / \mathrm{ml}$ concentration range were successfully amplified by PCR after purification by spin column kit (Table 1). Decreased performance of the commercial kit observed in samples with $10^{6} \mathrm{cfu} / \mathrm{ml}$ concentration could be attributed to the lower initial amount of sputum used in the process. All manual techniques employ a starting amount of $500 \mu \mathrm{l}$ of sputum, whereas a $200 \mu$ of material is used for the spin column kit as recommended by the manufacturer. Thus, for samples close to the assay sensitivity, this difference possibly affects PCR results. Modifications and/or additional column binding steps might be incorporated when spin columns. For pure cultures, waste water, artificially-infected EDTA-blood and lung tissue, it has been shown that a lysis buffer with proteinase $\mathrm{K}$ was 
sufficient to extract DNA for BCC DNA $[17,18]$.

Bacterial concentrations lower than $10^{6} \mathrm{cfu} / \mathrm{ml}$ could not be amplified by any of the purification techniques applied, thus the detection limit of recA PCR was $10^{6} \mathrm{cfu} /$ $\mathrm{ml}$ in the study. It was previously reported that regular recA PCR could detect $10^{6}$ cfu of BCC and DMSO significantly enhanced amplification of recA gene [2]. This observation was not verified in our study, where the most efficient amplification for the $1040 \mathrm{bp}$ recA target was obtained by using $200 \mathrm{mM}\left(\mathrm{NH}_{4}\right)_{2} \mathrm{SO}_{4}$ and $0.1 \%$ Tween 20 in the PCR master mix (data not shown).

Importance of this relative insensitivity of single round recA PCR is of debate in patients with chronic BCC infection or colonization, where bacterial loads of $10^{7}$ $10^{9} \mathrm{cfu}$ in sputum was previously noted [5]. Reducing the target amplicon size from 1040 bp to 465 bp is reported to provide only a 10 -fold increase in sensitivity $(2,5)$. For accomplishing a sensitivity of $1.2 \times 10^{1}$ to 1.3 $x 10^{2}$ cfu per gram of sputum, a semi-nested PCR is required, where consecutive genomovar identification must then be performed by direct sequencing, excluding RFLP analysis [5]. Drvinek et al. reported a nested PCR method with a first round of recA PCR, followed by a genomovar-specific amplification step with a sensitivity of $10^{3} \mathrm{cfu} / \mathrm{ml}$ [6]. FISH technique employed via a $16 \mathrm{~S}$ rRNA probe was reported to have $4 \times 10^{5} \mathrm{cfu} / \mathrm{ml}$ detection sensitivity when applied directly on sputum samples, but genomovar identification was not possible [19]. In a study by Vonberg et al., recA gene was targetted by a novel rapid-cycle PCR and genomovar-specific Flourescence Resonance Energy Transfer (FRET)

\section{References}

[1] Coenye T., VanDamme P., Govan J.R.W., Lipuma J.J. Taxonomy and identification of Burkholderia cepacia complex. J. Clin. Microbiol., 2001, 39, 3427-3446

[2] McDowell A., Mahenthiralingam E., Moore J.E. Dunbar K.E., Webb A.K., Dodd M.E., et al. PCRbased detection and identification of Burkholderia cepacia complex pathogens in sputum from cyctic fibrosis patient. J. Clin. Microbiol., 2001, 39, 42474255

[3] Shelly D.B., Spilker T., Gracely E.J., Coenye T., Vandamme P., Lipuma J.J.. Utility of commercial systems for identification of Burkholderia cepacia complex from cystic fibrosis sputum culture. J. Clin. Microbiol., 2000, 38, 3112-3115

[4] McMenamin J.D., Zaccone T.M., Coenye T., Vandamme P., Lipuma J.J. Misidentification of Burkholderia cepacia in U.S. cystic fibrosis treatment centers: an analysis of of 1051 recent sputum isolates. Chest, 2000, 117, 1661-1665 probes, offering another molecular method for BCC identification and typing [20]. Pyrosequencing and $r e c A$ real-time PCR had also been employed for BCC typing $[21,22]$. Recently, sensitivity of an optimized commercial fluorescent in situ hybridization (FISH) assay performed directly on sputum samples was determined as $8 \times 10^{5}$ $\mathrm{cfu} / \mathrm{ml}$, whereas a novel rRNA-based PCR assay with $100 \%$ sensitivity and specificity for all BCC species could detect $10^{4} \mathrm{cfu} / \mathrm{ml}$ of bacteria in sputa [23]. Diagnostic impact of molecular detection of BCC directly from patients' sputa and the most suitable techniques to be used for this purpose need to be determined.

In conclusion, the overall sensitivity of recA PCR from sputum was $10^{6} \mathrm{cfu} / \mathrm{ml}$ in our study which is appropriate for detecting chronic BCC infections in CF patients. Of the extraction methods evaluated; phenol-chloroform and commercial spin column kit performed better than other manual methods for extraction of experimentallyspiked BCC DNA from sputum for recA PCR.

\section{Acknowledgements}

Part of this study was supported by Hacettepe University Research Fund (Project NO: 0202 101027). Part of this study was presented as a poster in FEBS Congress, Istanbul, Turkey, 2006 (Yurdakul P, Ergunay K, Buber E, Sener B. Performance of different DNA extraction systems from sputum samples: a preliminary study. FEBS Journal, 273(Suppl.1):276, 2006).

[5] Moore J.E., Xu J., Millar B.C., Crowe M., Elborn J.S. Improved molecular detection of Burkholderia cepacia genomowar III and Burkholderia multivorans directly from sputum of patients with cystic fibrosis. J. Microbiol. Methods., 2002, 49, 183-191

[6] Drvinek P., Hrbackova H., Cinek O., Bartosova J., Nyc O., Nemec A., et al. Direct PCR detection of Burkholderia cepacia complex and identification of its genomowars by using sputum as source of DNA. J. Clin. Microbiol., 2002, 40, 3485-3488

[7] Honore-Bouakline S., Vincensini J.P., Giacuzzo V., Lagrange P.H., Herrmann J.L.. Rapid diagnosis of extrapulmonary tuberculosis by PCR: impact of sample preparation and DNA extraction. J. Clin. Microbiol., 2003, 41, 2323-2329

[8] Mahenthiralingam E., BischofJ., BryneS.K. Radomsky C. Davies J.E., Av-GayY., etal. DNA-based diagnostic approaches for identification of Burkholderia cepacia complex, Burkholderia vietnamiensis, Burkholderia 
multivorans, Burkholderia stabilis and Burkholderia cepacia genomovars I and II. J. Clin. Microbiol., 2000, 38, 3165-3173

[9] Sambrook J., Fritsch E.F., Maniatis T., Molecular cloning: a laboratory manual, 2nd ed., Cold Spring Harbor Laboratory Press, Cold Spring Harbor, 1989

[10] Wilson, K., Preparation of genomic DNA from bacteria, In: Ausubel F.M., Brent R., Kimgston R.E., Moore D.D., Seidman J.G., Smith J.A., Struhl K. (Eds), Current protocols in molecular biology. Greene Publishing Associates, Inc. and John Wiley \& Sons, Inc., New York, N.Y., 1990

[11] Lipuma J.J., Spilker T., Gill H.L., Campbell III P.W., Liu L., et al. Disproportionate distribution of Burkholderia cepacia complex species and transmissibility markers in cystic fibrosis. Am. J. Respir. Crit. Care. Med., 2001, 164, 92-96

[12] Kiska D.L., Kerr A., Jones M.C. Caracciolo J.A., Eskridge B., Jordan M., et al. Accuracy of four commercial systems for identification of Burkholderia cepacia and other gram-negative, nonfermenting bacilli recovered from patients with cystic fibrosis. J. Clin. Microbiol., 1996, 34, 886-891

[13] Henry D.A., Mahenthiralingam E., Vandamme P., Coenye T., Speert D.P. Biochemical and molecular approaches for determining genomovar status of the Burkholderia cepacia complex. J. Clin. Microbiol., 2001, 39, 1073-1078

[14] Mahenthiralingam E., Urban T.A., Goldberg J.B. The multifarious, multireplicon Burkholderia cepacia complex. Nature, 2005, 3, 144-156

[15] Payne G.W., Vandamme P., Morgan S.H., LiPuma J.L., Coenye T., Weightman A.J., et al. Development of a recA gene-based identification approach for the entire Burkholderia genus. Appl. Envir. Microbiol., 2005, 71, 3917-3927

[16] Yurdakul P., Ergunay K., Yalcın E., Doğru D, Sener B., Cobanoglu $\mathrm{N}$, et al. Burkholderia cepacia complex isolation and identification in a group of cystic fibrosis patients in Turkey. Mikrobiyol. Bult., 2006, 40, 301-306, (in Turkish)
[17] Merk S., Neubauer H., Meyer H., Greiseer-Wilke I. Comparison of different methods for the isolation of Burkholderia cepacia DNA from pure cultures and waste water. Int. J. Hyg. Environ. Health., 2001, 204, 127-131

[18] Merk S., Meyer H., Greiseer-Wilke I., Sprague D., Neubauer H. Detection of Burkholderia cepacia DNA from artificially infected EDTA-blood and lung tissue comparing different DNA isolation methods. J. Vet. Med., 2006, 53, 281-285

[19] Hogardt M., Trebesius K., Geiger A.M., Hornef M., Rosenecker J., Heesemann J.. Specific and rapid detection by Fluorescent In Situ Hybridization of bacteria in clinical samples obtained from cystic fibrosis patients. J. Clin. Microbiol., 2000, 38, 818-825

[20] Vonberg R.P., Haussler S., Vandamme P., Steinmetz I.. Identification of Burkholderia cepacia complex pathogens by rapid-cycle PCR with fluorescein hybridization probes. J. Med. Microbiol., 2005, 55, 721-727

[21] Slinger R., Yan L., Myers R., Ramotar K., St Denis M., Aaron S.D. Pyrosequencing of a recA gene variable region for Burkholderia cepacia complex genomovar identification. Diagn. Microbiol. Infect. Dis., 2007, 58, 379-84

[22] Pimentel J.D., Dubedat S.M. Identification of isolates within the Burkholderia cepacia Complex by a multiplex recA and $16 \mathrm{~S}$ rRNA gene real-time PCR assay. J. Clin. Microbiol., 2007, 45, 3853-3854

[23] Brown A.R., Gowan J.R.W. Assessment of Fluorescent In Situ Hybridization and PCR-Based methods for rapid identification of Burkholderia cepacia Complex organisms directly from sputum samples. J. Clin. Microbiol., 2007, 45, 1920-1926 